\title{
Evaluation of the Effect of Ultrasonic Degassing on Components Produced by Low
}

\section{Pressure Die Casting.}

Manel da Silva ${ }^{1,2 *}$, Liceth Rebolledo ${ }^{1}$, Thomas Pabel ${ }^{3}$, Tose Petkov ${ }^{3}$, Xavier Planta ${ }^{4}$, Jaume Tort $^{5}$, Dmitry Eskin ${ }^{6,7}$

${ }^{1}$ ASCAMM Technology Centre, Cerdanyola del Vallès, 08290, Spain

${ }^{2}$ Universitat Autonòma de Barcelona, Cerdanyola del Vallès, 08193, Spain

${ }^{3}$ Austrian Foundry Research Institute, 8700 Leoben, Austria

${ }^{4}$ Ultrasion, S.L., Cerdanyola del Vallès, 08290, Spain

${ }^{5}$ Hornos y Metales, S.A., Ajalvir, 28864, Spain

${ }^{6}$ Brunel University, Brunel Centre for Advanced Solidification Technology, Uxbridge, UB8 3PH, United Kingdom

${ }^{7}$ Tomsk State University, Tomsk, 634050 , Russian Federation

*Corresponding author: Manel da Silva López, PhD., Phone: +34 95447 00,

Fax: +34 95447 11: e-mail: mdasilva@ascamm.com,

Postal address: ASCAMM Technology Centre - Av. Universitat Autònoma, 23 - E-08290 -

Cerdanyola del Vallès - SPAIN 


\begin{abstract}
Ultrasonic processing is known to be an efficient means of aluminium melt degassing with additional benefits of being economical and environment friendly. This paper describes the performance of ultrasonic degassing in preparing melt for low pressure die casting. Efficiency of ultrasonic degassing is compared with conventional Ar rotary degassing, by direct measurements of hydrogen concentration in the melt with a Foseco Alspek-H probe and by reduced-pressure test in different stages of the casting process. Significant reduction in dross formation along with the similar efficiency of hydrogen degassing was shown for ultrasonic degassing as compared with conventional Ar rotary degassing. The mechanical properties, microstructure and porosity level of components produced by low pressure die casting after both degassing techniques are determined. The results show that the components produced after ultrasonic degassing treatment have similar hardness, tensile properties, porosity level and microstructure as the components degassed with conventional Ar rotary degassing.
\end{abstract}

Keywords: Ultrasonic treatment, Aluminum alloy, Degassing, Casting, Hydrogen, Mechanical properties 


\section{Introduction}

The practical importance of degassing for liquid aluminium comes from highly variable solubility of hydrogen that is relatively high in the liquid aluminium and very small in solid aluminium. As a result, during solidification the excess hydrogen precipitates and in most cases gets trapped between solid aluminium grains forming gas porosity or adding to shrinkage porosity. Oxides present in the melt in a form of particles or films further contribute to the porosity. This porosity is a major casting defect causing poor ductility, low fatigue resistance and strength of a casting.

Hydrogen finds its way into liquid aluminium through atmospheric moisture (water vapour reacts with aluminium to produce alumina and hydrogen) and hydrocarbon-containing gases in furnace atmosphere. Liquid metal in a melting furnace can be supersaturated in hydrogen and tend to naturally degas to the so-called quasi-equilibrium hydrogen level that is a function of atmospheric pressure, temperature and humidity ${ }^{1}$. The kinetics of degassing and re-gassing upon to ultrasonic processing has been recently studied ${ }^{2}$. The natural degassing takes time and is, therefore, impractical. In industry, various methods are used to accelerate the hydrogen precipitation (degassing), including stirring, inert gas purging and vacuum. Ultrasonic degassing has an advantage of being able to reach hydrogen levels $50 \%$ lower than the quasi-equilibrium concentration ${ }^{3}$. This level of degassing is inevitably followed by natural re-gassing to the quasi-equilibrium levels, but can be retained if casting follows shortly after degassing is finished ${ }^{2}$.

Ultrasonic degassing of liquid metals has long history. As early as in the 1940s Esmarch et al. studied the degassing of $\mathrm{Al}-\mathrm{Mg}$ alloys by sonic vibrations induced by contactless electromagnetic stirring and vibrations in the crucible ${ }^{4}$. In 1950 Bradfield reported the works of Turner on degassing of molten aluminum and its alloys by direct introduction of ultrasonic oscillations into the melt at $15 \mathrm{kHz}$ and $26 \mathrm{kHz}^{5}$. And in the same year Eisenreich compared 
vacuum ultrasonic degassing with vacuum degassing, degassing with chlorine lancing, and sonic and ultrasonic degassing ${ }^{6}$. He pointed out the potential of ultrasonic processing but also mentioned related practical difficulties. Sergeev noted that despite high potential of ultrasonic degassing there is a challenge in transferring sufficient ultrasonic power to a large mass of liquid metal ${ }^{7}$. Starting from the 1960 s successful laboratory and pilot-scale trials of ultrasonic degassing for foundry and later wrought alloys have been performed and summarized in a series of publications by G.I. Eskin ${ }^{3,8}$. In these works the practical issues such as equipment selection (water-cooled magnetostrictive transducers) and sonotrode materials selection $(\mathrm{Nb}$ and $\mathrm{Nb}$-based alloys) were solved and justified.

Kapustina $^{9}$ gave a thorough analysis of ultrasonic degassing mechanisms in water and concluded that the most important role is played by the oscillations of the bubbles in the acoustic field, while ultrasonic cavitation takes the supportive role in intensification of the bubble formation and acceleration of bubble/liquid interfacial diffusion. G.I. Eskin ${ }^{3,8,10}$ argued that the cavitation is essential for ultrasonic degassing of metallic melts where the natural gas bubbles are not typically present, unlike those in water. Therefore, the formation and multiplication of bubbles (essential for degassing) can be only achieved in liquid metals by cavitation. Indeed, already early investigations conducted by Altman et al. ${ }^{11}$ demonstrated that the removal of hydrogen from aluminium alloys depends greatly on the acoustic power transferred to the melt and on the development of cavitation.

Despite successful industrial trials in the 1960-1970s, ultrasonic degassing was not adopted as a mainstream technology due to arrival of Ar-assisted rotary or impeller degassing. In recent years, the intrinsic features of ultrasonic degassing - such as absence of rotating parts, no requirement for gas usage and clean environment - stipulated comeback interest to this technology that may answer the current environmental challenges. In addition, new level of ultrasonic technology makes its application easier. 
This paper reports the results of pilot-scale trials of ultrasonic degassing as applicable to one of major foundry technologies, i.e. low-pressure die casting.

\section{Experimental Procedure}

\subsection{Ultrasonic degassing equipment}

The experiments were conducted using a prototype specifically designed to treat large volumes of molten aluminium. The device allowed the movement of the ultrasonic transducer and wave-guiding system vertically and circumferentially, as shown in Fig. 1.

The ultrasonic equipment used in the experiments was composed of: a USGC-5-22 MS ultrasonic generator, an MST-5-18 water-cooled magnetostrictive transducer, a titanium booster, all supplied by Reltec (Russia), and a niobium tip. Fig. 2 shows the assembled ultrasonic degassing equipment used in the experiments.

\subsection{Melt treatment procedure}

An AlSi7Mg0.3 (A356) alloy modified with 200 ppm of Sr was molten and heated up to a temperature of $725 \pm 5^{\circ} \mathrm{C}$ in a resistance furnace with an inner crucible with a diameter of 500 $\mathrm{mm}$ and a depth of $500 \mathrm{~mm}$ (Nabertherm, Germany). The total amount of melt was $150 \mathrm{~kg}$.

In order to acquire more information and be able to compare the degassing efficiency of the ultrasonic degassing treatment with the conventional Ar-assisted degassing by a Foseco rotary degasser, it was decided to increase the initial hydrogen content in the melt. A tablet of Hydral $\left(\mathrm{Al}(\mathrm{OH})_{3}\right)$ was added to the molten metal prior to the degassing treatment.

Measurements of the hydrogen content with an Alspek H Mini probe (Foseco, Germany) and Reduced Pressure Test (RPT) (MK, Germany) were made before and after the Hydral tablet was applied, after the degassing procedure in the melting furnace and after the melt transfer to a casting furnace. The reduced pressure test compares the densities of samples solidified in air and under a reduced pressure of approximately $80 \mathrm{mbar}$, the reduced pressure enhances pore 
formation and pore expansion, giving a visibly more porous sample than the one solidified under atmospheric conditions. Porosity assessment is done using the Archimedean Principle and the resulting density index (DI) is calculated using the formula:

$$
D I[\%]=\frac{D_{a t m}-D_{v a c}}{D_{a t m}} \cdot 100
$$

The results of RPT test can be influenced by the amount of oxide films in the melt so it acts more like a technological probe for porosity propensity, while the Alspek measurements give direct readings reflecting hydrogen removal from the melt. In this sense, the Alspek measurements give more direct assessment of degassing (removal of dissolved hydrogen) which is the subject of this paper.

The degassing process was done using two different methods, a conventional Foseco degassing unit with Ar purging (FDU) and the ultrasonic prototype. These two cleaning methods were separately applied to a $150 \mathrm{~kg}$ melt under the same melting conditions (including Hydral addition).

The ultrasonic and rotary degassing treatments were both applied for 15 min with a melt temperature of $725 \pm 5^{\circ} \mathrm{C}$. The following parameters were used for the ultrasonic treatment, assuring cavitation conditions in the melt:

- Vibration amplitude: $25 \mu \mathrm{m}$

- Vibration frequency: $17.5 \mathrm{kHz}$

- Rotating velocity of the sonotrode: $1 \mathrm{rpm}$

- Vertical movement: $30 \mathrm{~mm}$ up and down

- Sonotrode's tip depth below the melt surface: 40-70 mm

The conventional Foseco rotary degassing unit, Fig. 3, introduces very fine bubbles of a dry inert gas (Ar) into the melt, through a spinning graphite rotor which generates the bubbles at the base of the melt volume. The bubbles rising through all areas of the molten aluminium 
volume absorb dissolved hydrogen. Argon was applied for 15 min with a flow rate of $6 \mathrm{l} / \mathrm{min}$ and a rotational speed of $600 \mathrm{rpm}$.

\subsection{Component casting and evaluation}

The production of the cast components was made using a Low Pressure Die Casting Unit (Kurtz AK92). For the casting production melt was transferred from the melting furnace where degassing was performed to the LPDC furnace. A double cavity step plate mould developed by ÖGI was used to cast the specimens (Fig. 4).

In order to achieve constant and reproducible casting and cooling conditions the ingot moulds were temperature controlled with a dual circuit heating and cooling device. The measurement of the temperature of the ingot moulds was carried out by casing thermal elements (model k ICE 584.1, Class 1, calibrated) which were positioned in boreholes placed at intervals of $5 \mathrm{~mm}$ from the inner wall of the ingot mould. Once the temperature indicated on the thermal element reached the set value, the form was opened, the sample was taken, and afterwards the ingot was closed and tempered for the next casting.

The mould temperature at the start of each casting process was $260^{\circ} \mathrm{C}$. The step plate mould was finished by an isolating coating (DYCOTE F140). For each degassing treatment (Foseco rotary degassing and ultrasonic degassing) 14 castings were made. Measurements of the air pressure, humidity and temperature were made during melting, degassing and casting processes.

From each part the hardness were measured and 4 tensile bars were machined from the 10-mm step according to DIN 50125 - B 5 x 25 (Fig. 5). In the subsequent tensile tests according to EN 10002-1, 0.2\% yield strength $\mathrm{R}_{\mathrm{p} 0.2}$, tensile strength $\mathrm{R}_{\mathrm{m}}$ and elongation at fracture A were determined in a universal testing machine (Zwick Roell $250 \mathrm{kN}$ ).

In addition, the microstructure of the parts was evaluated in an optical microscope (Olympus BX51) taking specimens from the regions indicated in Fig. 5. The porosity was 
measured following the VDG P 201 "Volume deficits of castings made of non-ferrous metals" on the basis that the images were taken in a defined 25-fold magnification. The images were converted in 8-bit greyscale images and the porosity was determined by defining a threshold grey value. The pores detected in the image are coloured red and the surface components in relation to the detection frame (ROI - Region of Interest) are evaluated by percentage. The respective ROIs have to be selected in a way to cover a maximum possible area and they must be adapted to the contour of the subregions. The accuracy is specified as $\pm 0.1 \%$.

The grain size was characterized by the linear intercept method on images obtained with an optical microscope with polarized light.

\section{Experimental Results and Discussion}

\subsection{Melt quality and dross formation}

The dross formation was monitored by skimming the melt surface, weighing and visual examination, Fig. 6 . The results are compiled in Table 1.

The advantage of ultrasonic degassing process is obvious. Dross formation is related to the disturbance of the melt surface with entrapment of existing and formation of new oxide films. This oxide layer with inclusions of aluminum (50-80\%) gradually builds up at the

surface and should be removed before casting, representing direct metal losses ${ }^{1}$. Part of the metal can be recovered by special recycling procedures done usually ex-foundry. Rotary degassing using impeller and gas purged through the melt from the bottom creates highly turbulent conditions in the melt with forced upward bubble movement and vortex formation at the melt surface, enhancing dross formation as reported by Campbel1 ${ }^{12}$.

Ultrasonic processing, on the contrary, creates very small cavities that are turned into hydrogen bubbles, with the flow direction downwards. These bubbles then grow in the acoustic field, extracting hydrogen dissolved in the liquid phase, and naturally float to the surface without turbulence and surface disturbance. As a result, dross formation is limited. 
Ar-rotary degassing is known for additional cleaning of the melt of oxide inclusions that adhere to the bubble surface and float along to the surface ${ }^{12}$. According to literature, ultrasonic degassing has similar effect ${ }^{3}$ where the oxide inclusions are associated with cavitation bubbles. Cleaning of the melt of oxide inclusions, therefore, cannot explain the massive difference in dross formation in the two tested degassing techniques.

The efficiency of degassing is similar for the two degassing technologies. The results of the reduced pressure test compared with the direct hydrogen measurements by Foseco Alspek H Analyser are displayed in Tables 2 and 3.

The gas content in the molten metal after applying conventional Ar-rotary degassing is lower than after ultrasonic degassing $(0.31 \mathrm{vs} 0.41 \mathrm{ml} / 100 \mathrm{~g})$. However, the final hydrogen content, once the metal is transferred to the LPDC crucible, remains on the same level for both processes $(0.47 \mathrm{vs} 0.45 \mathrm{ml} / 100 \mathrm{~g})$. This actually shows that the tendency to melt regassing is higher in the case of the conventional process, which can be also related to the dross formation ${ }^{13}$.

It should be also noted that RPT results may reflect the decreased porosity that is not only due to the decreased hydrogen concentration but also due to the decreased amount of oxide inclusions ${ }^{12}$. Somewhat higher values of the density index for samples after ultrasonic degassing show that the residual amount of oxide films in this case is greater than after Ar degassing. However, the cleaning of the melt from oxides was not the subject of this study that is focused on degassing proper.

\subsection{Microstructure and porosity}

The microstructures of the cross sections of castings produced after both cleaning procedures are typical for this type of alloy and consist of the primary Al-solid solution and $((\mathrm{Al})+\mathrm{Si})$-eutectic. The eutectic silicon phase is fully modified and very finely distributed.

Fig. 7 shows the microstructures of the samples produced after FDU and ultrasonic degassing. 
In addition to main structural elements, there are only isolated Fe-containing precipitates detectable in the form of "Chinese script" and needle shape. The intermetallic compounds should be $\mathrm{FeMg}_{3} \mathrm{Fe}_{6} \mathrm{Al}_{8}$ and $\mathrm{FeSiAl}_{5}$ phases, respectively ${ }^{14}$. In the microstructure there are no indications of over modification such as polygonal $\mathrm{Al}_{2} \mathrm{Si}_{2} \mathrm{Sr}$ intermetallic phases or coarsened Si-eutectic. Non-metallic inclusions, i.e. oxides and oxide films, have not been detected.

Fig. 8 shows the porosity analysis performed on the polished specimens. It can be observed that the porosity present in both specimens is on the same level $(1.7 \%$ for after rotary degassing and $1.5 \%$ after US degassing), corroborating that the degassing efficiency obtained with the ultrasonic degassing prototype is comparable to the degassing efficiency of a mature industrial technology such as the rotary degassing. It also shows that the possible difference in residual oxide concentration resulted from a degassing technology does not play decisive role in the porosity formation.

The grain size in the castings produced after either degassing technology does not differ much as can be seen in Fig. 9 and Table 4. Literature extensively reports grain refining after ultrasonic treatment ${ }^{8}$. However, as mentioned by Atamanenko et al. ${ }^{15}$, grain refinement typically requires presence of some grain refining substrates that can be activated by cavitation processing. In this work, the high temperature with melt superheating exceeding $100{ }^{\circ} \mathrm{C}$ at which the ultrasonic treatment was applied, absence of specially added grain refining agents, and the subsequent melt transfer to the LPDC crucible clearly limited the grain refining effect of the ultrasonic treatment.

\subsection{Mechanical properties}

The average hardness values of the castings produced after both treatments are 54-56 HB, which is around the minimum hardness of $55 \mathrm{HB}$ 5/250 required by EN 1706:2010 for this alloy. 
The standardized tensile properties listed in EN 1706 are only valid for separately cast test bars. In castings the ultimate tensile strength and $0.2 \%$ yield strength should be a minimum of $70 \%$ and the elongation a minimum of $50 \%$ of the values required for the separately cast test bars. Table 5 presents the average tensile properties of specimens (from 2 different castings) tested for each degassing process and the comparison to the required values in EN 1706:2010 for an AlSi7MgKF alloy.

The tensile strength and the $0.2 \%$-yield strength are similar for the rotary and US degassing samples taken from castings. The US degassing samples have a higher elongation than the impeller-degassed samples. With taking into account the very small variation in grain size in the samples produced after either degassing method (Fig. 9), this level of properties shows that the amount of defects that can influence the strength and ductility, e.g. pores and oxide inclusions, is at least similar after both degassing techniques. In comparison to the required values in EN 1706:2010 for the samples taken from the components, the tensile strength $\mathrm{Rm}$, the $0.2 \%$ - yield strength $\mathrm{Rp} 0.2$ and the elongation A were significantly higher than the minimum requirements.

\section{Conclusions}

From the results obtained in the present study the following conclusions can be inferred:

- Ultrasonic degassing performed using a single ultrasonic source and a prototype-level setup is able to achieve similar degassing performance as a mature, commercially available Ar-rotary degasser for an appreciable melt volume of $150 \mathrm{~kg}$.

- The melt surface is much less disturbed during ultrasonic degassing, as cavitation bubbles are formed within the metal and the flow is directed downwards. As a result, much less dross formation is observed as compared to Ar-rotary degassing. 
- Mechanical properties of castings produced after ultrasonic degassing or Ar-rotary degassing are similar with some tendency of improved ductility after ultrasonic degassing.

\section{Acknowledgements}

The authors would like to acknowledge the financial support provided by the European Union's Seventh Framework Program managed by REA - Research Executive Agency (FP7/2007-2013) under Grant Agreement number 286344 (www.ultragassing.eu). The authors gratefully acknowledge all help provided by the members of the consortium.

\section{References}

1. J., Campbell: 'Castings', $2^{\text {nd }}$ edn, 2003, Butterworth-Heinemann, Oxford.

2. N., Alba-Baena and D., Eskin: 'Kinetics of ultrasonic degassing of aluminum alloys', Proc. 'Light Metals 2013', 957-962, 2013, Hoboken, Wiley.

3. G.I., Eskin:' Ultrasonic Treatment of Light Alloy Melts', 1998, Gordon and Breach, Amsterdam.

4. W., Esmarch, T., Rommel and K., Benther: 'Werkstof f-Sonderheft', 78-87, 1940, W.V. Siemens Werke, Berlin.

5. G., Bradfield: 'Summarized Proceedings of Symposium on Applications of Ultrasonics', Proc. Phys. Soc. B, 63, 305-321, 1950.

6. H., Eisenreich: 'Entgasung von Aluminium Legirungen', Die Technik, 5, 310-315, 1950.

7. S.V. Sergeev: 'Physical and Chemical Properties of Liquid Metals', 1952, Oborongiz, Moscow.

8. G.I., Eskin: 'Ultrasonic Treatment of Molten Aluminum', 1965, Metallurgiya, Moscow. 
9. O.A., Kapustina: 'Degassing of Liquids', Proc. 'Physical Principles of Ultrasonic Technology', 253-336, 1970, Moscow, Rozenberg.

10. G.I., Eskin: 'Cavitation Mechanism of Ultrasonic Melt Degassing', Ultrason. Sonochem., 2, 137-141, 1995.

11. M.B., Altman, D.V., Vinogradova, V.I., Slotin and G.I., Eskin: 'On the Effects of Ultrasound on Molten Metals', Izv. Akad. Nauk SSSR, Otd. Tekhn. Nauk, 9, 25-30, 1958.

12. J., Campbell: 'Complete Casting Handbook', 893-896, 2011, Oxford, ButterworthHeinemann.

13. N., Alba-Baena, T., Pabel, N., Villa-Sierra and D., Eskin: 'Effect of ultrasonic melt treatment on degassing and structure of aluminium alloys', Mater. Sci. Forum, 2013, 765, $271-275$.

14. M., da Silva López. 'Mechanical and microstructural analysis of light alloys produced by New Rheocasting', Ph.D. Thesis, Universidad de Navarra, San Sebastián, Spain, 2006, 133135.

15. T.V., Atamanenko, D.G., Eskin, L., Zhang, L., Katgerman.: 'Criteria of Grain Refinement Induced by Ultrasonic Melt Treatment of Aluminum Alloys Containing Zr and Ti', Metall. Mater. Trans. A, 2010, 41A, 2056-2066.

\section{FIGURE CAPTIONS}

1. Functioning scheme of the ultrasonic degassing mechanism.

2. Waveguiding system (left) and ultrasonic degassing prototype (right).

3. Foseco degassing unit (FDU).

4. Step plate mould (left) and casting (right). 
5. Position and designation of the samples tensile bars (long red bars), hardness (green square) and metallographic samples (short blue bars).

6. Dross collected after Foseco rotary degassing treatment (left) and after ultrasonic degassing treatment (right).

7. Microstructures of FDU (top) and ultrasonic (bottom) samples, magnification $=200 \mathrm{x}$ (left) and 500x (right).

8. FDU sample: porosity $=1.7 \%$ (left); ultrasonic sample: porosity $=1.5 \%$ (right)

9. Grain size with linear intercept mesh of the FDU sample (left) and ultrasonic sample (right).

\section{TABLE CAPTIONS}

Table 1. Dross formation.

Table 2. Hydrogen content for Foseco rotary degassing unit (FDU) treatment

Table 3. Hydrogen content for ultrasonic treatment.

Table 4. Results of the grain size measurements.

Table 5. Average mechanical properties and comparison to the minimum required values in EN 1706:2010. 
Table 1. Dross formation.

\begin{tabular}{|c|c|c|c|}
\hline & \multicolumn{2}{|c|}{ Weight } & Comment \\
& {$[\mathrm{g}]$} & {$[\%]$} & Extremely high metallic content \\
\hline After FDU & 1800 & 1.20 & Low metallic content \\
\hline After US & 340 & 0.23 & \\
\hline
\end{tabular}

Table 2. Hydrogen content for Foseco rotary degassing unit (FDU) treatment

\begin{tabular}{|c|c|c|c|c|c|c|c|}
\hline & \multirow{2}{*}{$\begin{array}{c}\text { H-Content } \\
{[\mathrm{ml} / 100 \mathrm{~g}]}\end{array}$} & \multirow{2}{*}{$\begin{array}{c}D I \\
{[\%]}\end{array}$} & \multirow{2}{*}{$\begin{array}{c}\text { Air } \\
\text { pressure } \\
\text { [hPa] }\end{array}$} & \multicolumn{2}{|c|}{ Humidity } & \multicolumn{2}{|c|}{ Temperature } \\
\hline & & & & rel. [\%] & abs. $\left[\mathrm{g} / \mathrm{m}^{3}\right]$ & $\operatorname{Air}\left[{ }^{\circ} \mathbf{C}\right]$ & Melt $\left[{ }^{\circ} \mathrm{C}\right]$ \\
\hline Before Hydral & 0.26 & 1.69 & 1019 & 51 & 13.87 & 28 & 726 \\
\hline After Hydral & 0.59 & 17.10 & 1019 & 52 & 14.14 & 28 & 723 \\
\hline After FDU & 0.31 & 0.53 & 1019 & 50 & 14.36 & 29 & 730 \\
\hline After melt transferred & 0.48 & 3.28 & 1016 & 42 & 15.76 & 34 & 725 \\
\hline
\end{tabular}

Table 3. Hydrogen content for ultrasonic treatment.

\begin{tabular}{|c|c|c|c|c|c|c|c|}
\hline & \multirow{2}{*}{$\begin{array}{l}\text { H-Content } \\
{[\mathrm{ml} / \mathbf{1 0 0 g}]}\end{array}$} & \multirow{2}{*}{$\begin{array}{c}D I \\
{[\%]}\end{array}$} & \multirow{2}{*}{$\begin{array}{c}\text { Air } \\
\text { pressure } \\
\text { [hPa] }\end{array}$} & \multicolumn{2}{|c|}{ Humidity } & \multicolumn{2}{|c|}{ Temperature } \\
\hline & & & & rel. [\%] & abs. $\left[\mathrm{g} / \mathrm{m}^{3}\right]$ & $\operatorname{Air}\left[{ }^{\circ} \mathrm{C}\right]$ & Melt $\left[{ }^{\circ} \mathrm{C}\right]$ \\
\hline Before Hydral & 0.28 & 2.77 & 1019 & 55 & 14.96 & 28 & 727 \\
\hline After Hydral & 0.61 & 15.86 & 1020 & 57 & 14.67 & 27 & 718 \\
\hline After Ultrasonic & 0.41 & 5.93 & 1020 & 56 & 14.41 & 27 & 731 \\
\hline After melt transferred & 0.45 & 6.72 & 1013 & 42 & 14.95 & 33 & 730 \\
\hline
\end{tabular}


Table 4. Results of the grain size measurements.

\begin{tabular}{|c|c|c|}
\hline Sample & $\begin{array}{c}\text { Average Grain Size } \\
{[\boldsymbol{\mu m}]}\end{array}$ & $\begin{array}{c}\text { Macro Grain Size } \\
\text { (according to ASTM E112-96) }\end{array}$ \\
\hline FDU & $389 \pm 16$ & $\mathrm{M}-12.9$ \\
\hline Ultrasound & $325 \pm 12$ & $\mathrm{M}-13.3$ \\
\hline
\end{tabular}

Table 5. Average mechanical properties and comparison to the minimum required values in EN 1706:2010.

\begin{tabular}{|c|c|c|c|}
\hline \multicolumn{1}{|c|}{ Sample No. } & \multicolumn{1}{|c|}{$\boldsymbol{R}_{\mathbf{p 0 , 2}}$} & $\boldsymbol{R}_{\mathrm{m}}$ & $\boldsymbol{A}$ \\
& {$[\mathrm{MPa}]$} & {$[\mathrm{MPa}]$} & {$[\%]$} \\
\hline FDU & $76 \pm 3$ & $170 \pm 3$ & $7.9 \pm 1.0$ \\
\hline \multicolumn{1}{|c|}{ Ultrasound } & $76 \pm 2$ & $173 \pm 4$ & $9.0 \pm 1.3$ \\
\hline Minimum required values for a test bar & 63 & 119 & 1.3 \\
taken from a casting (EN AC-AISi7MgKF, & & & \\
EN 1706:2010) & & & \\
\hline
\end{tabular}




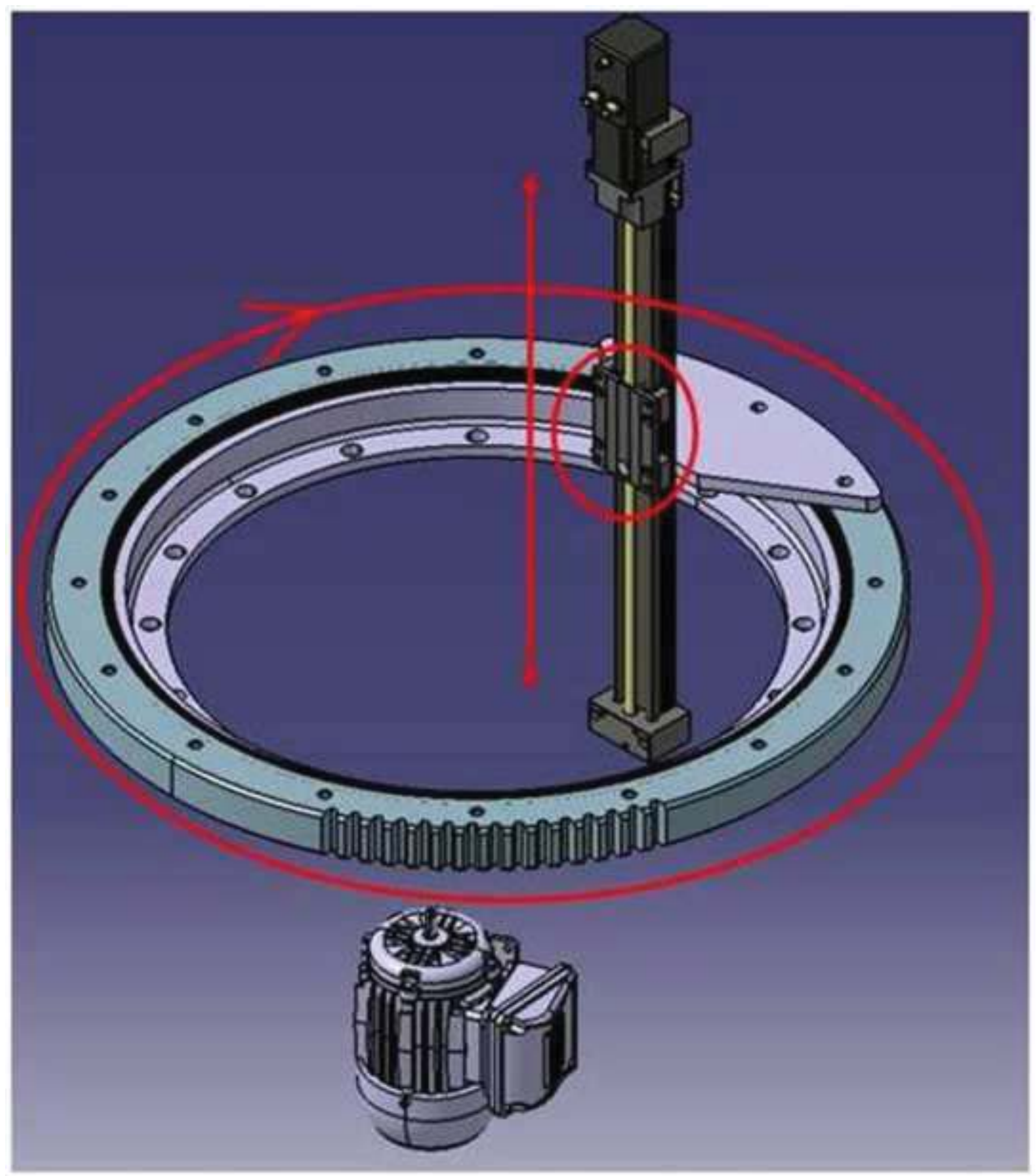




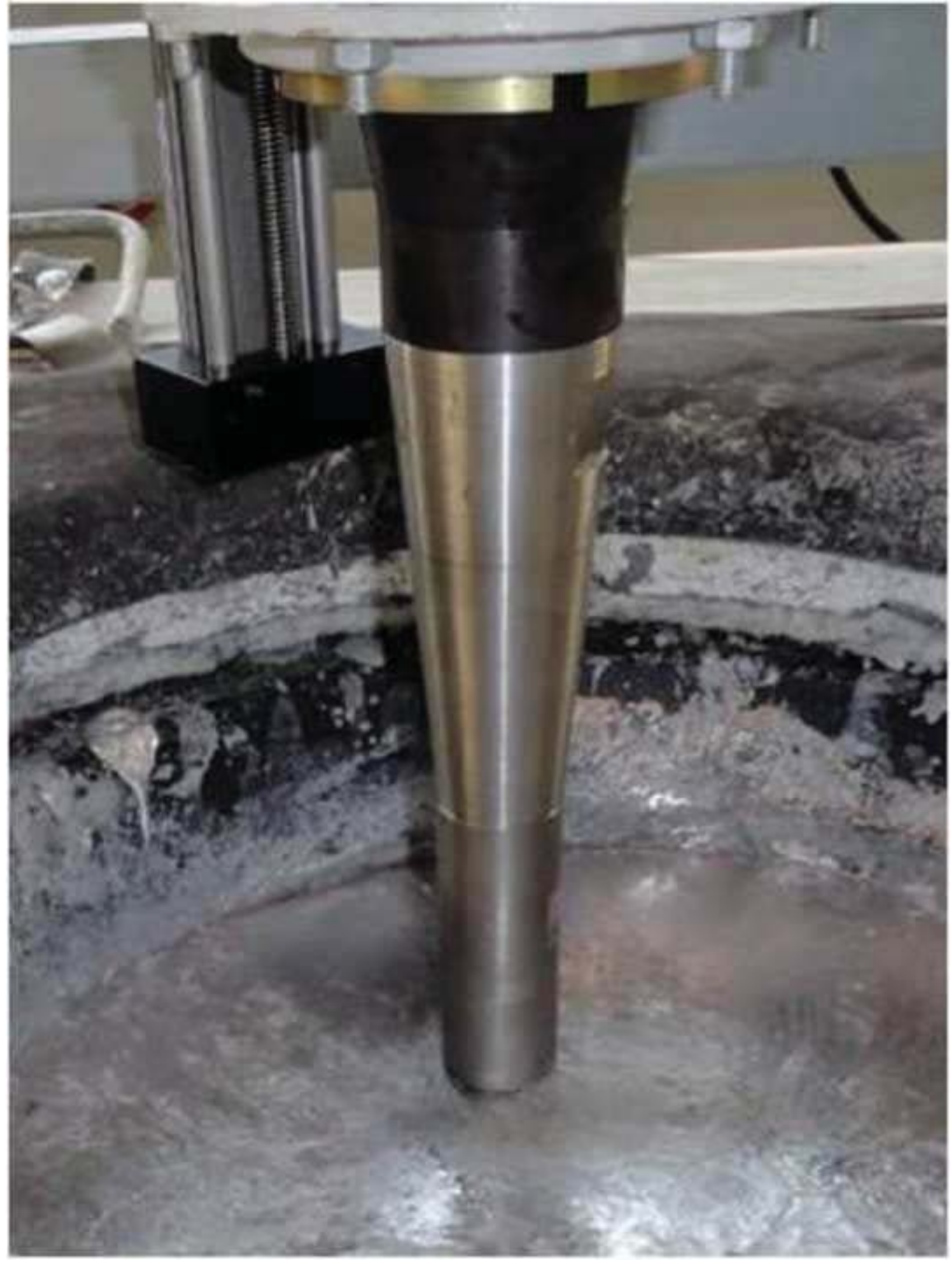




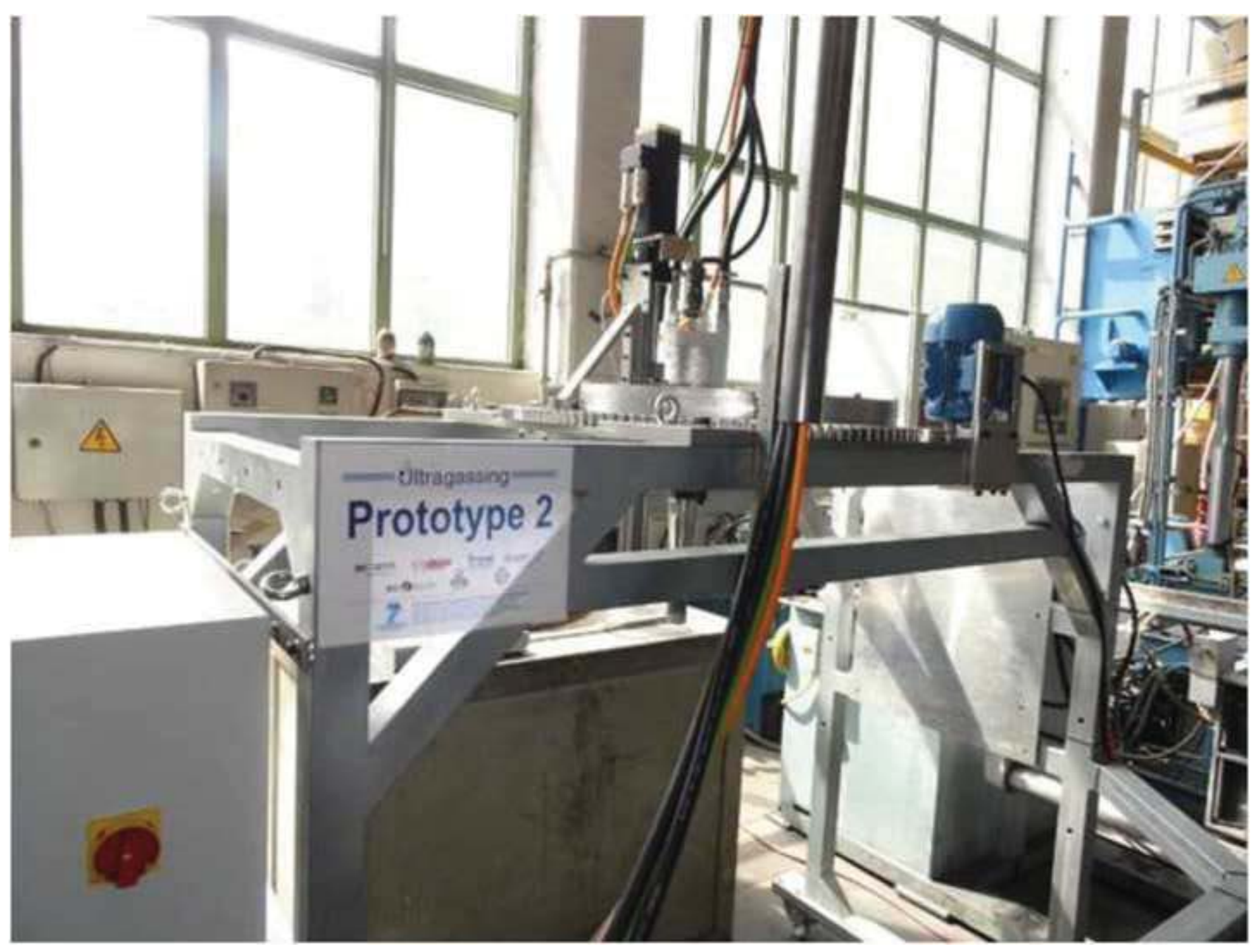




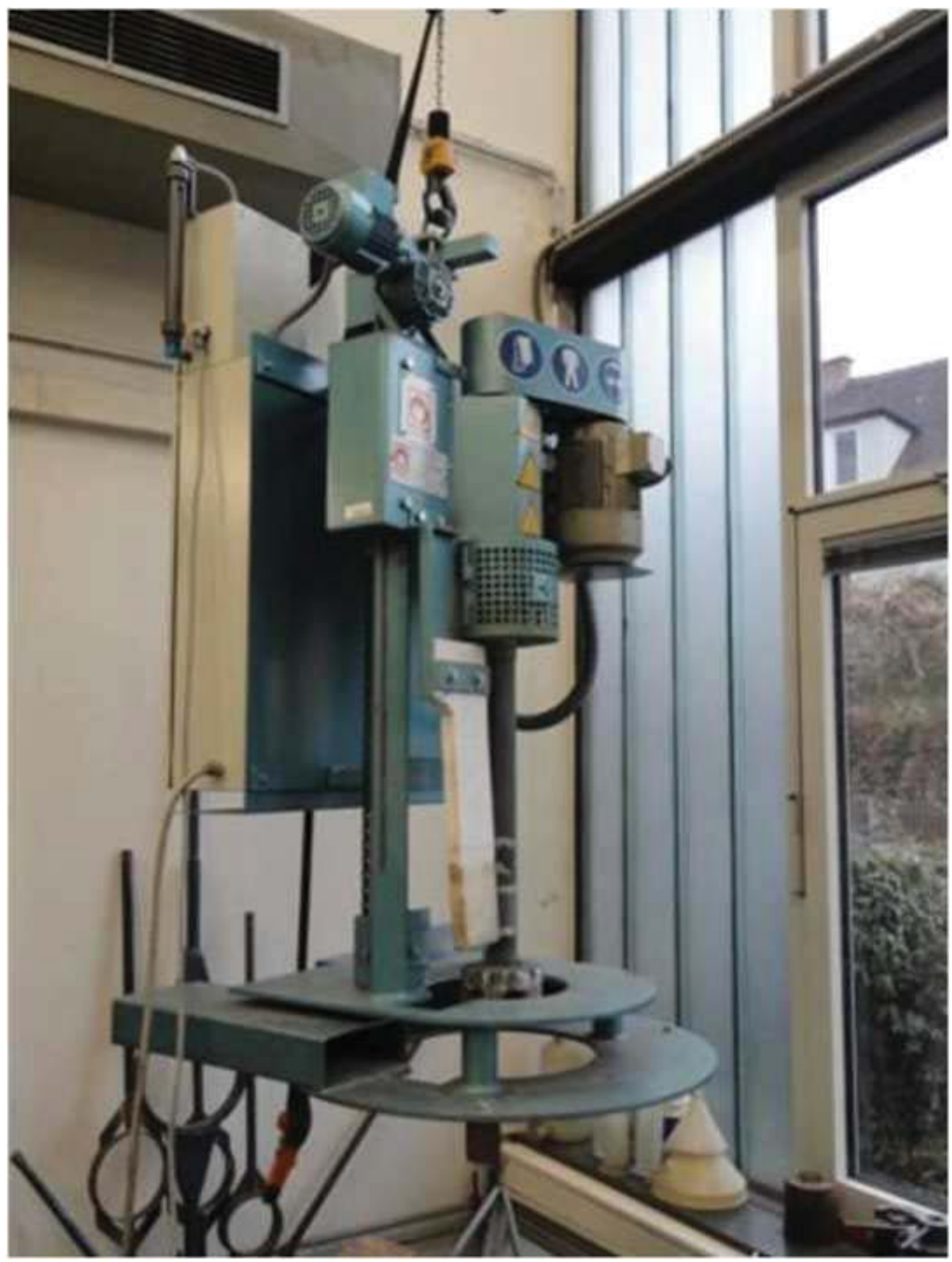



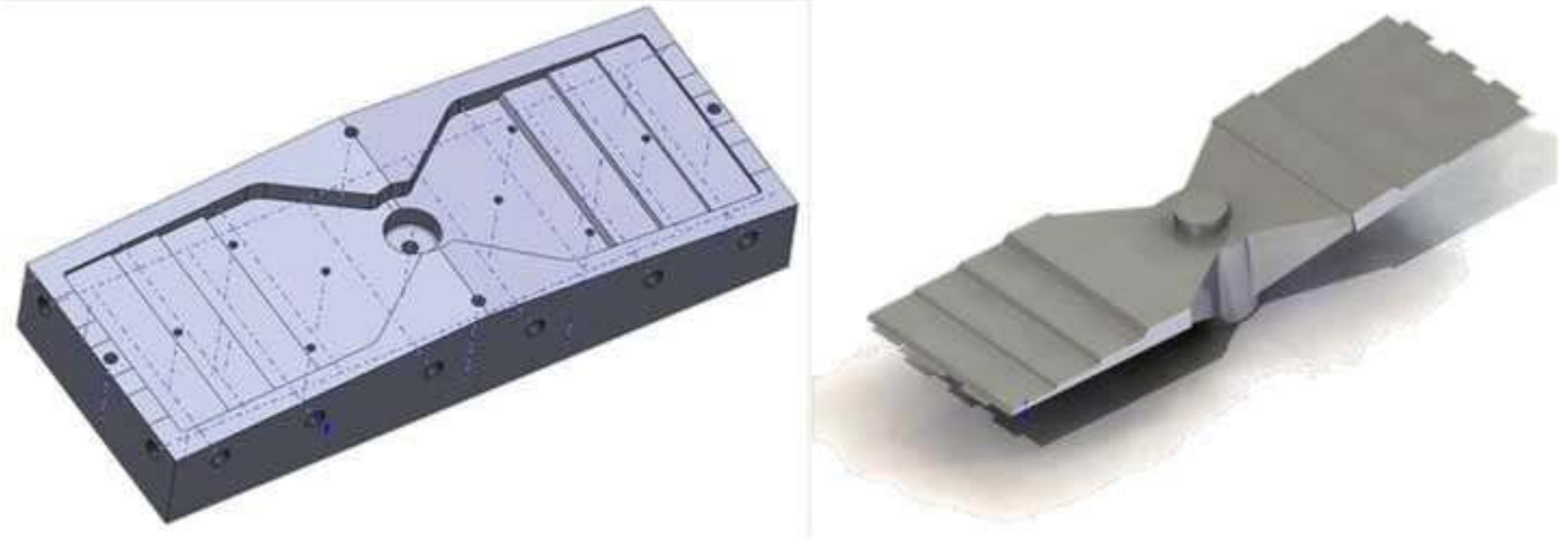


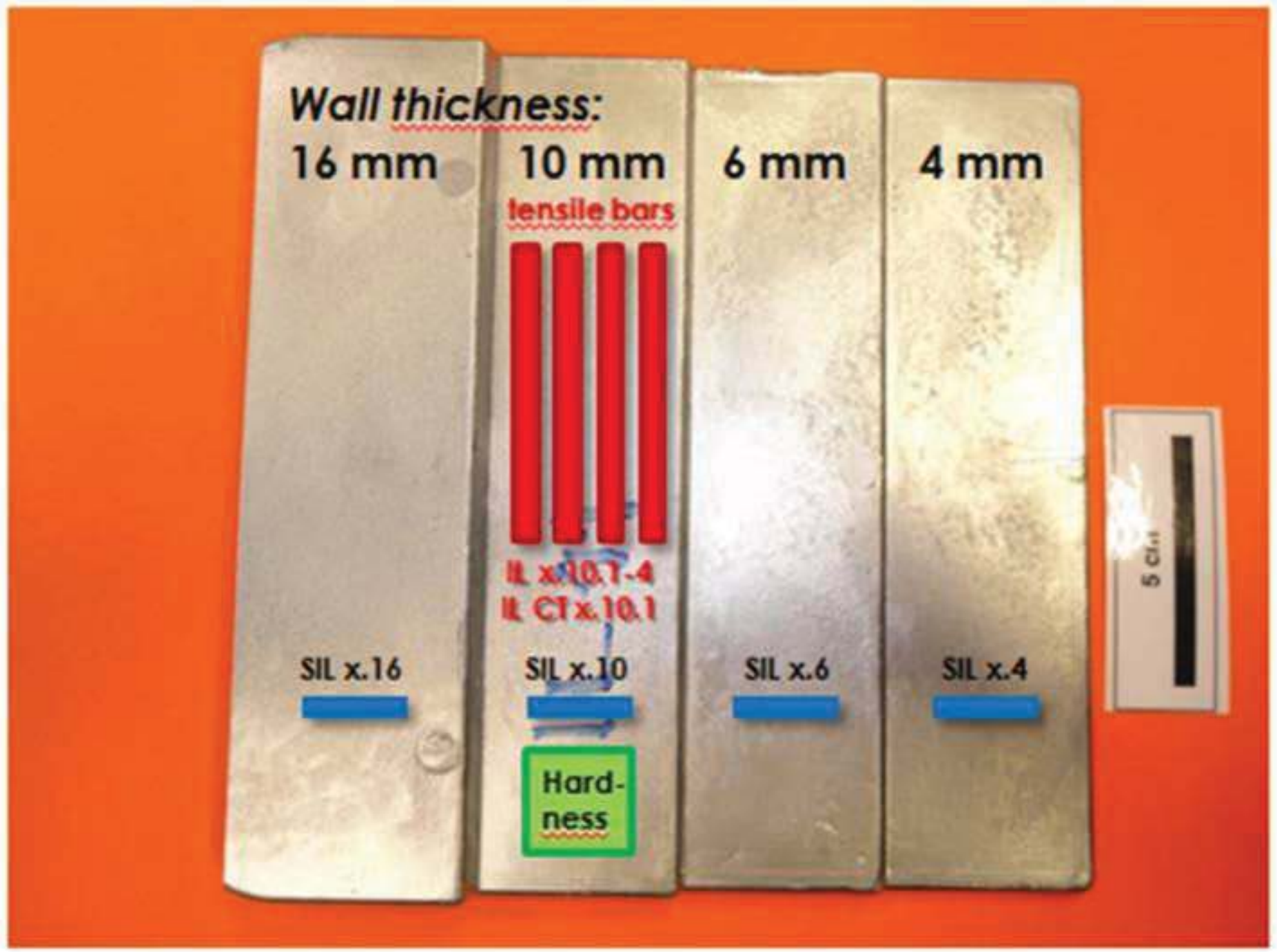




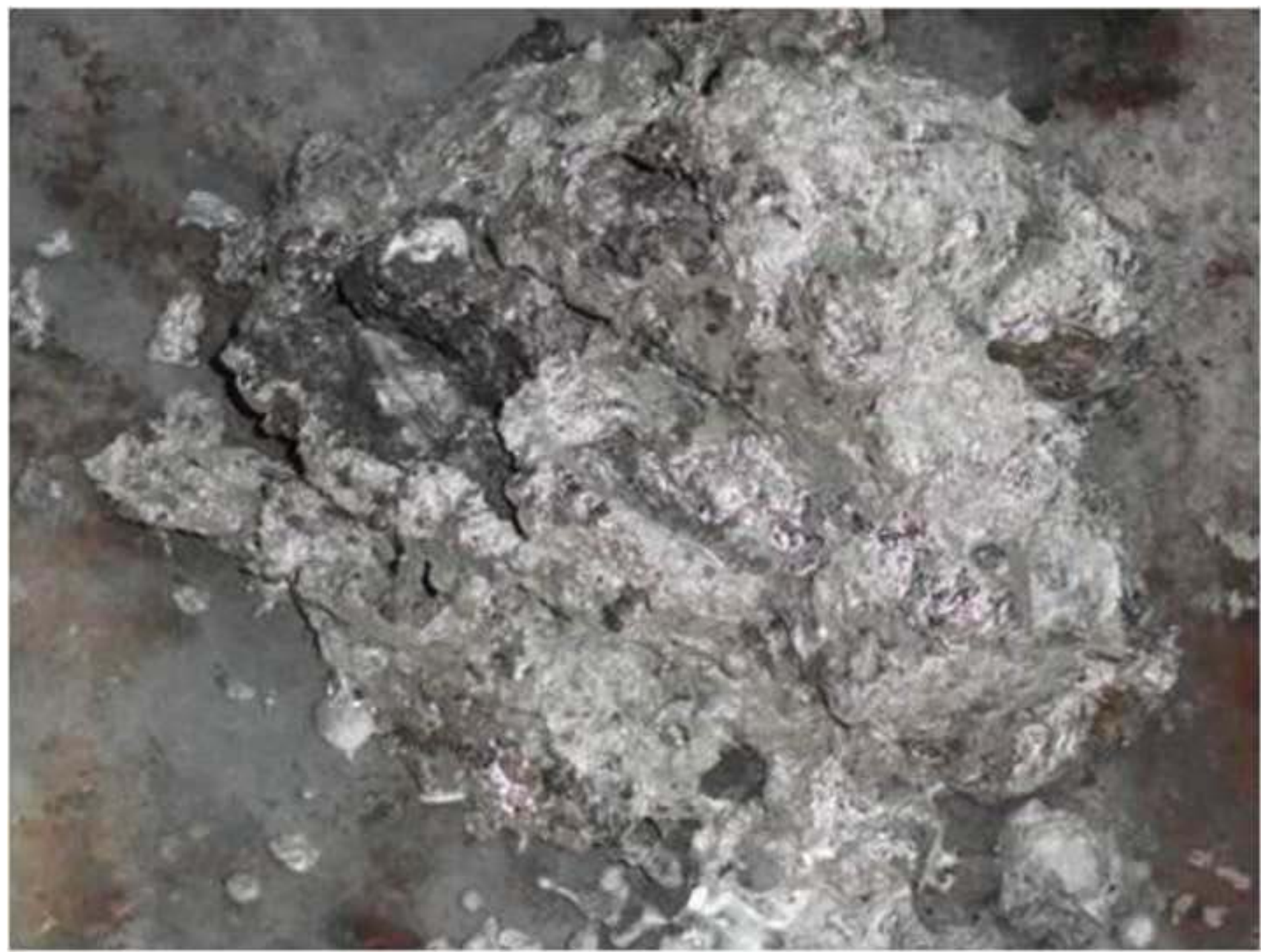




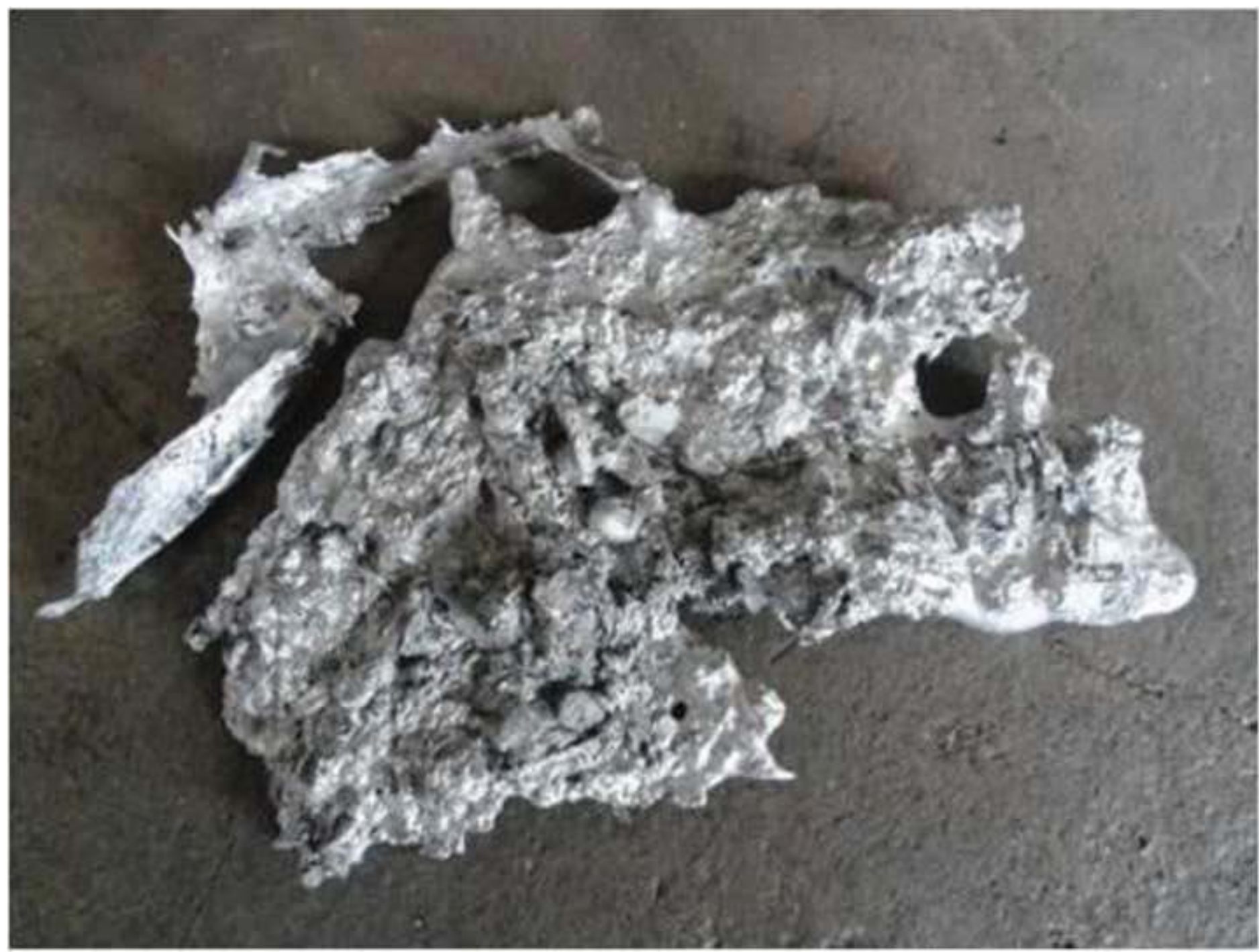




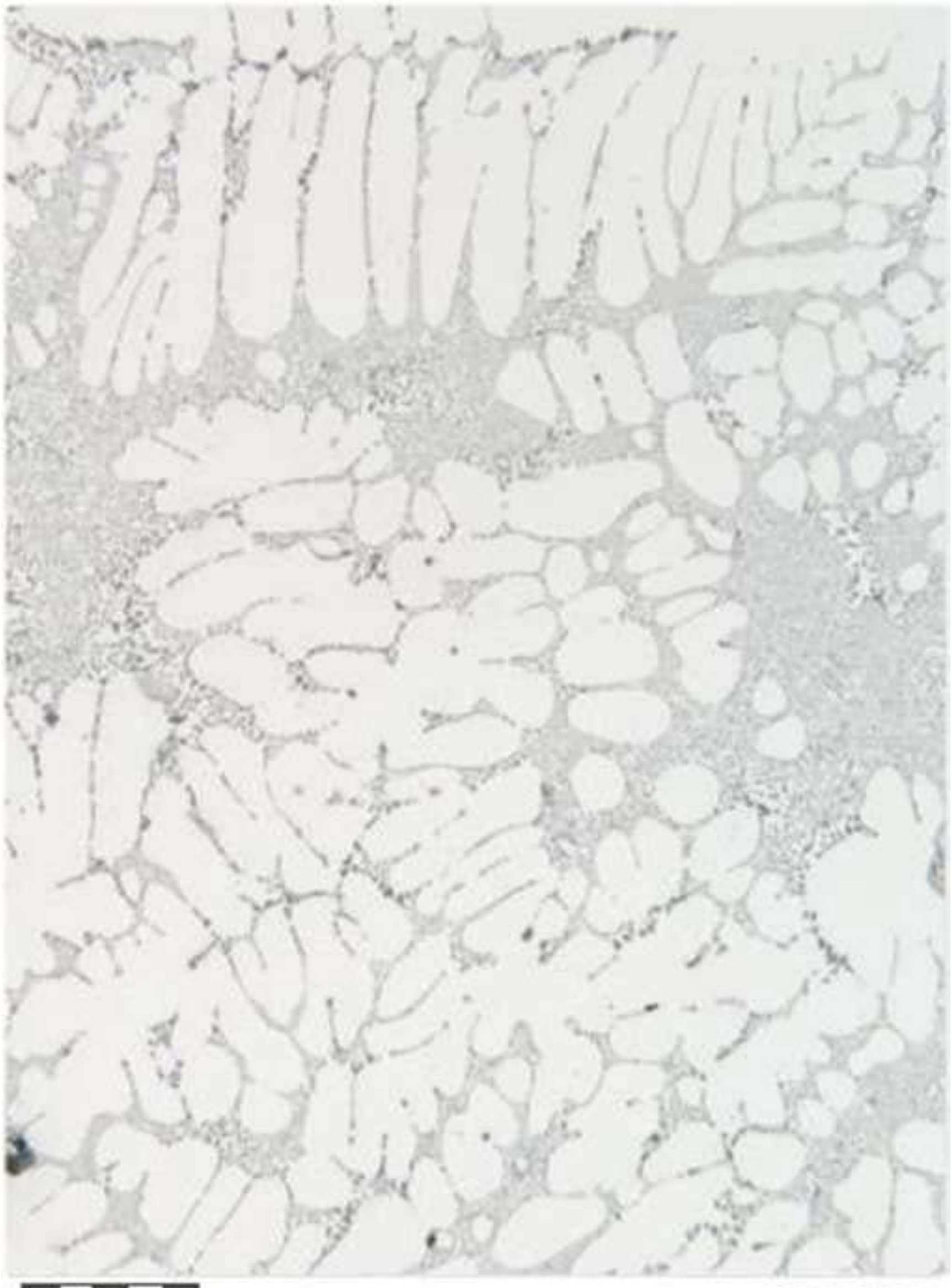




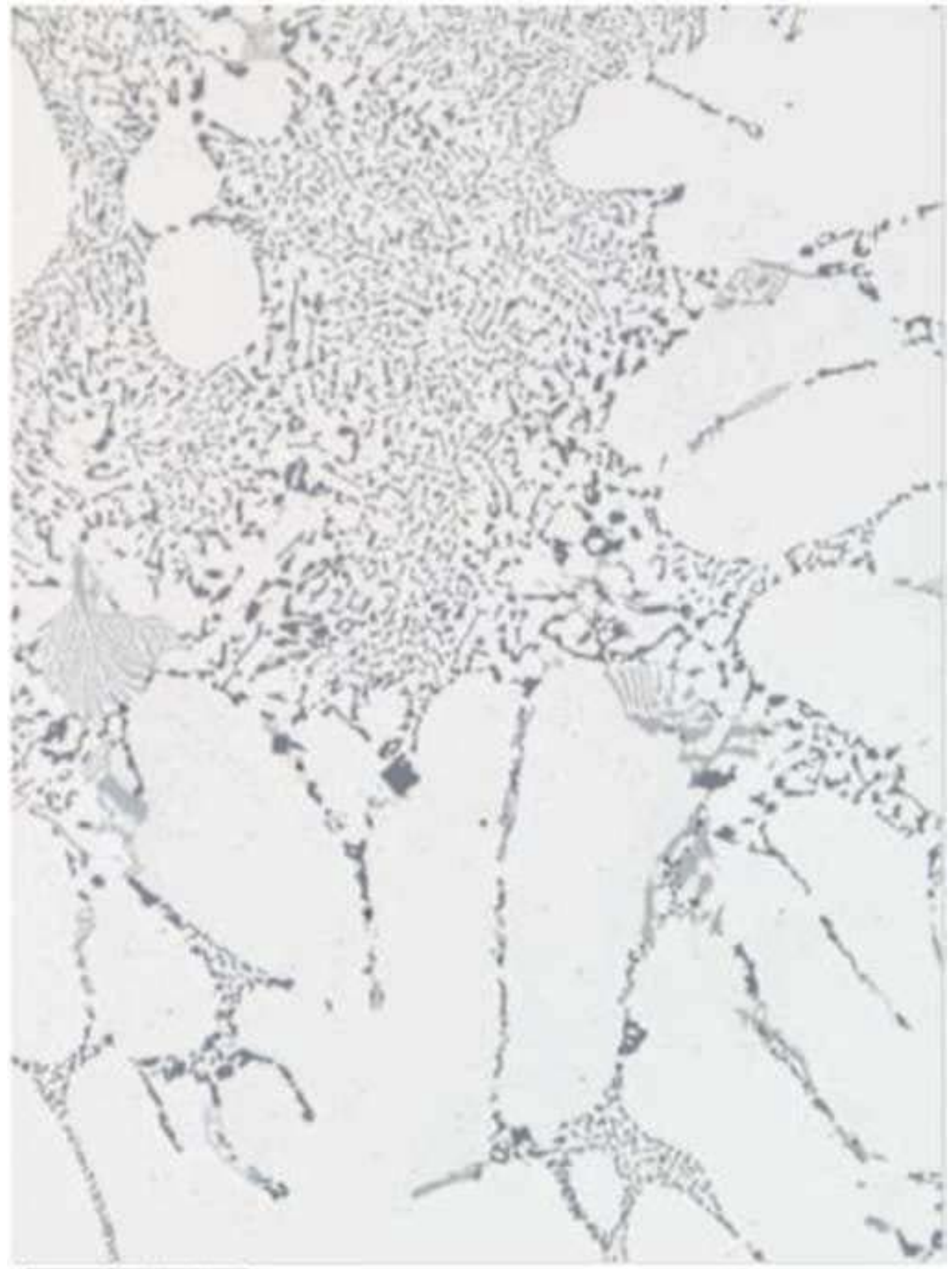




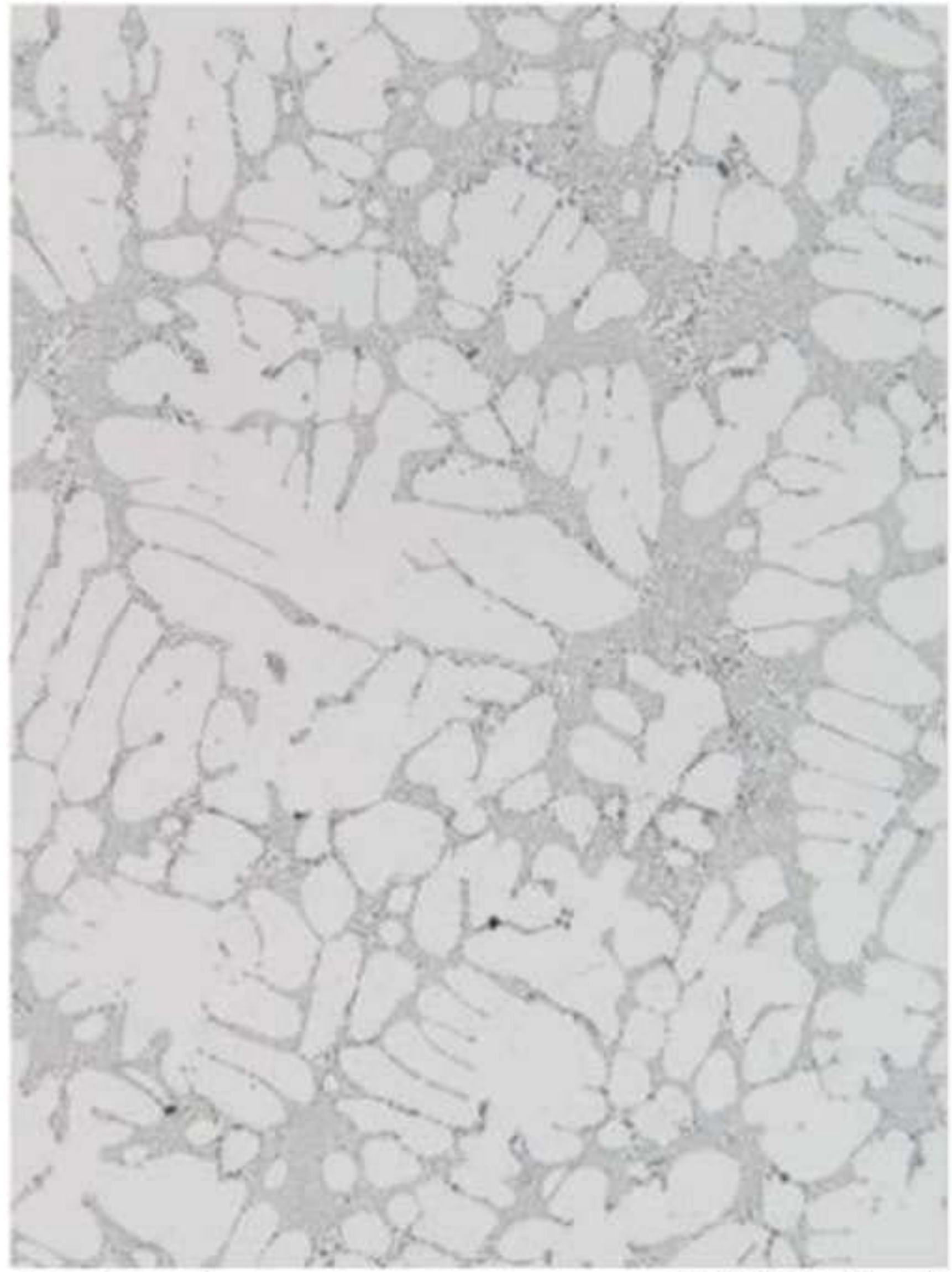




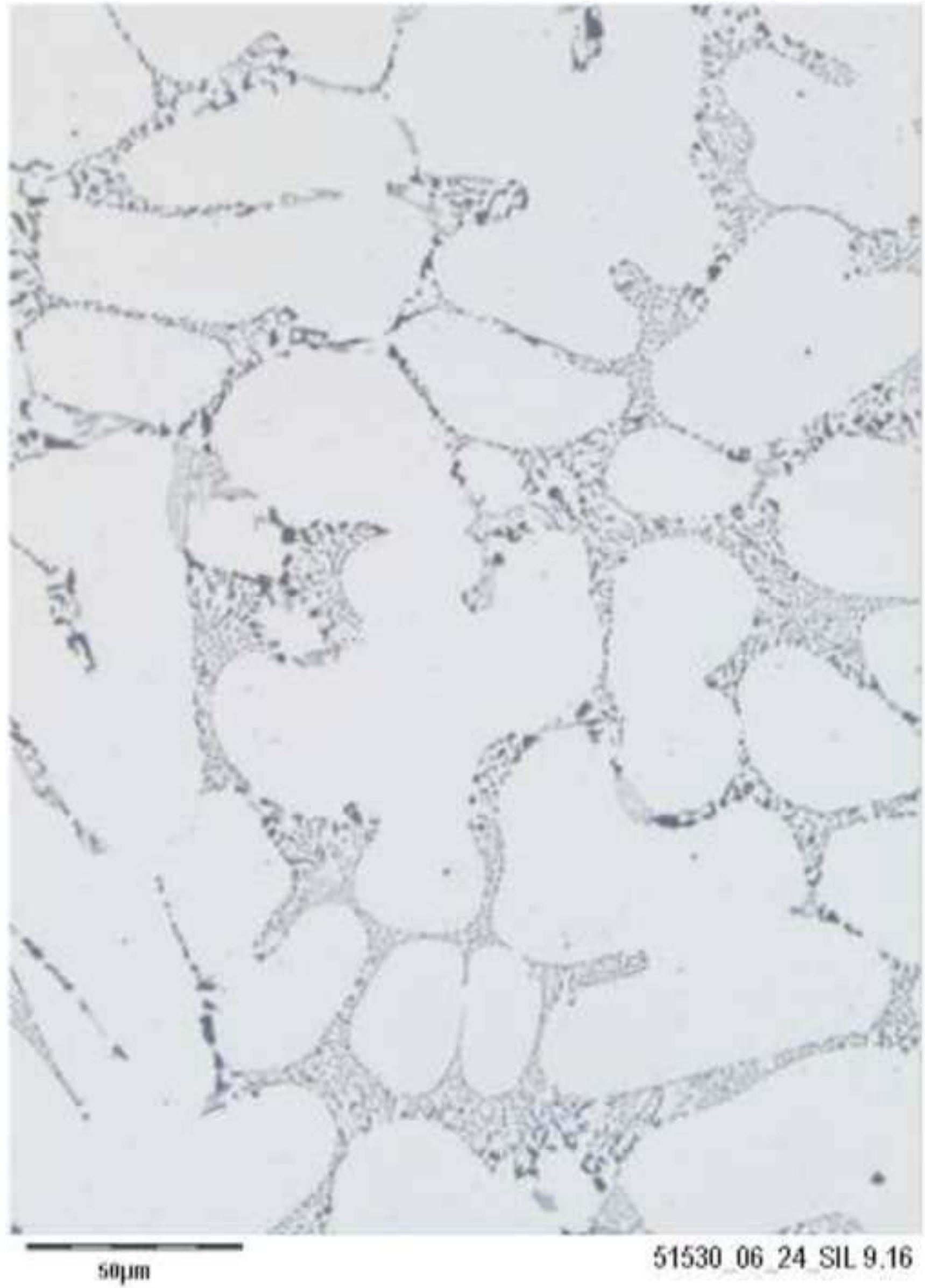




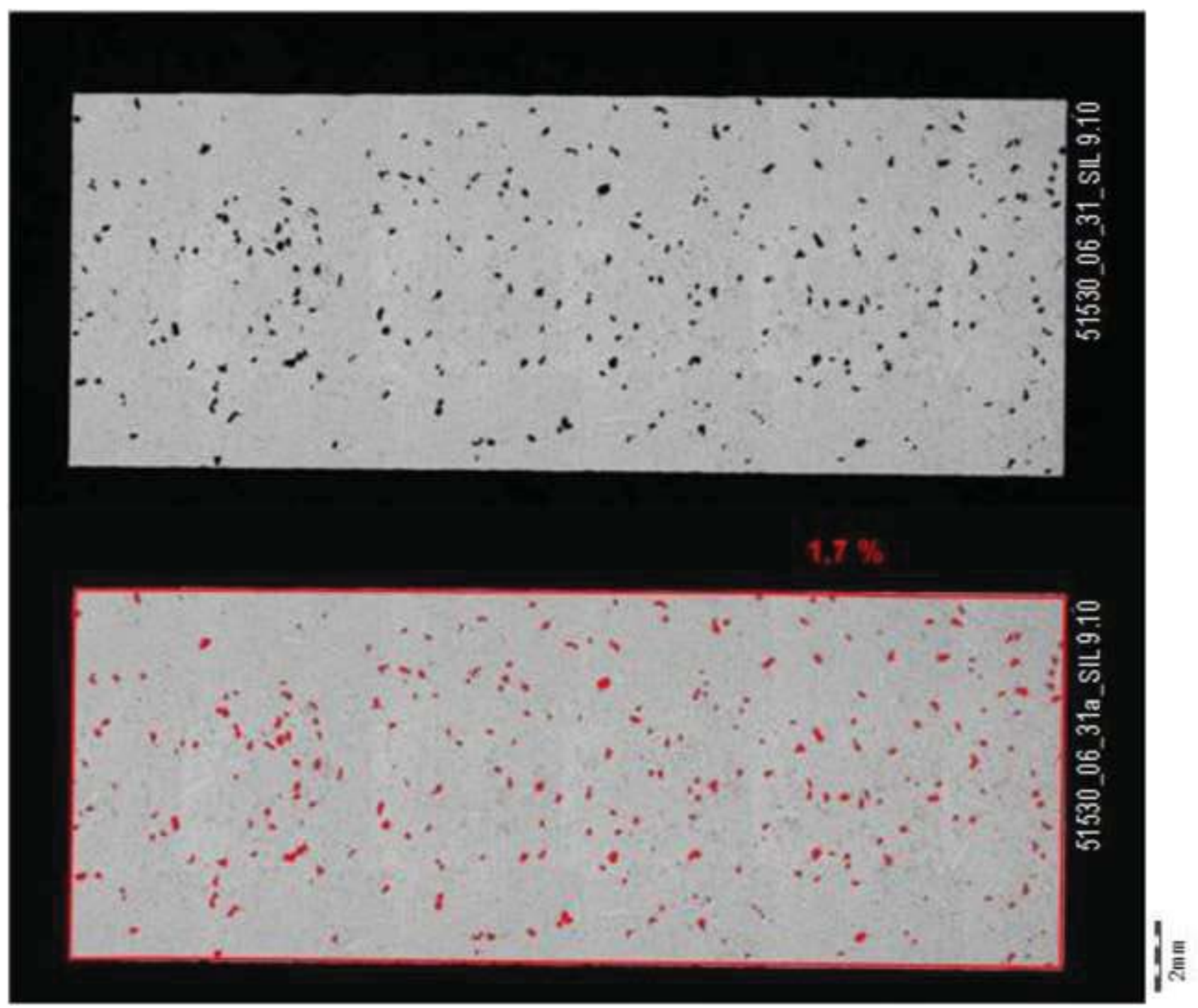




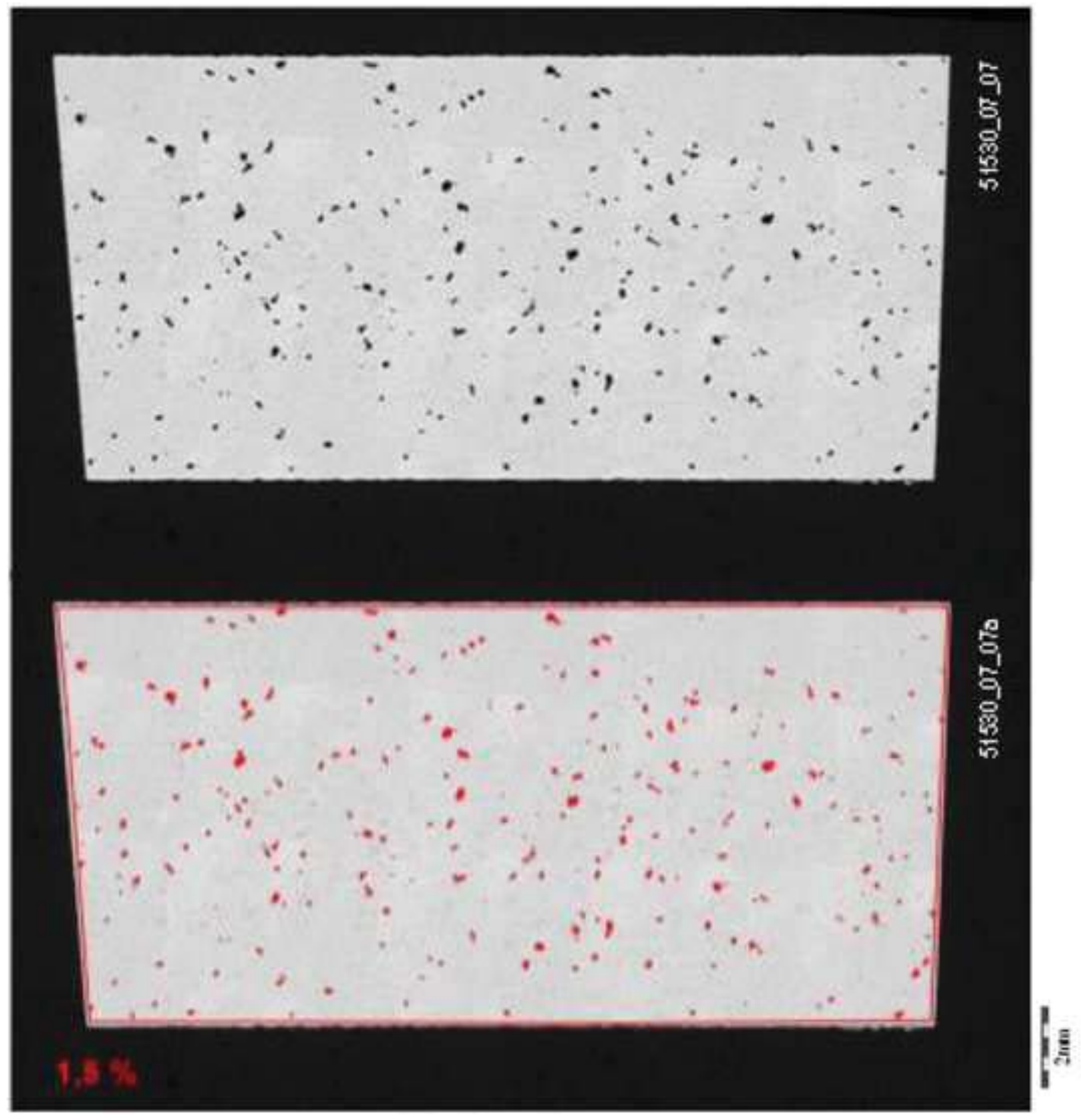




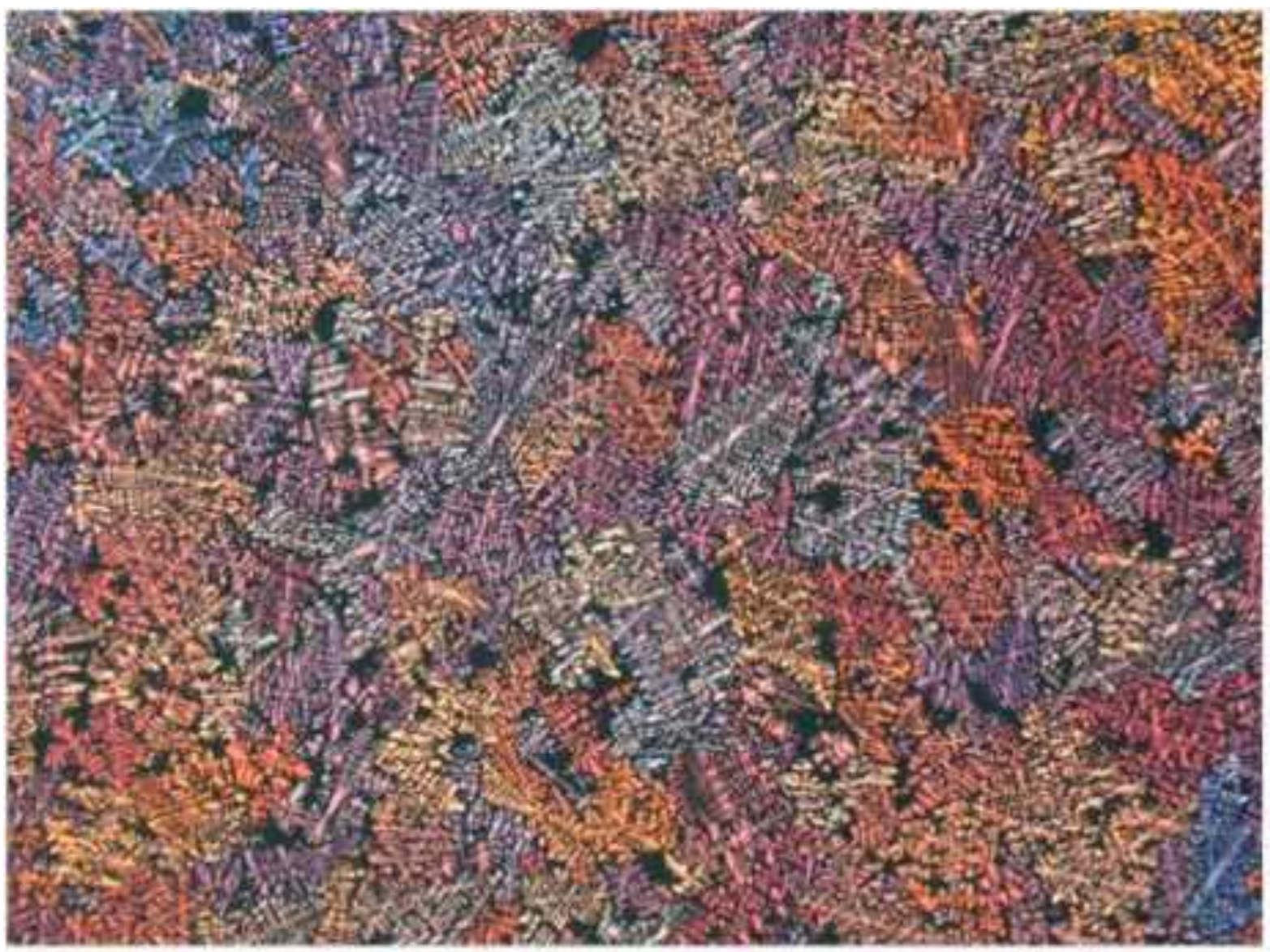

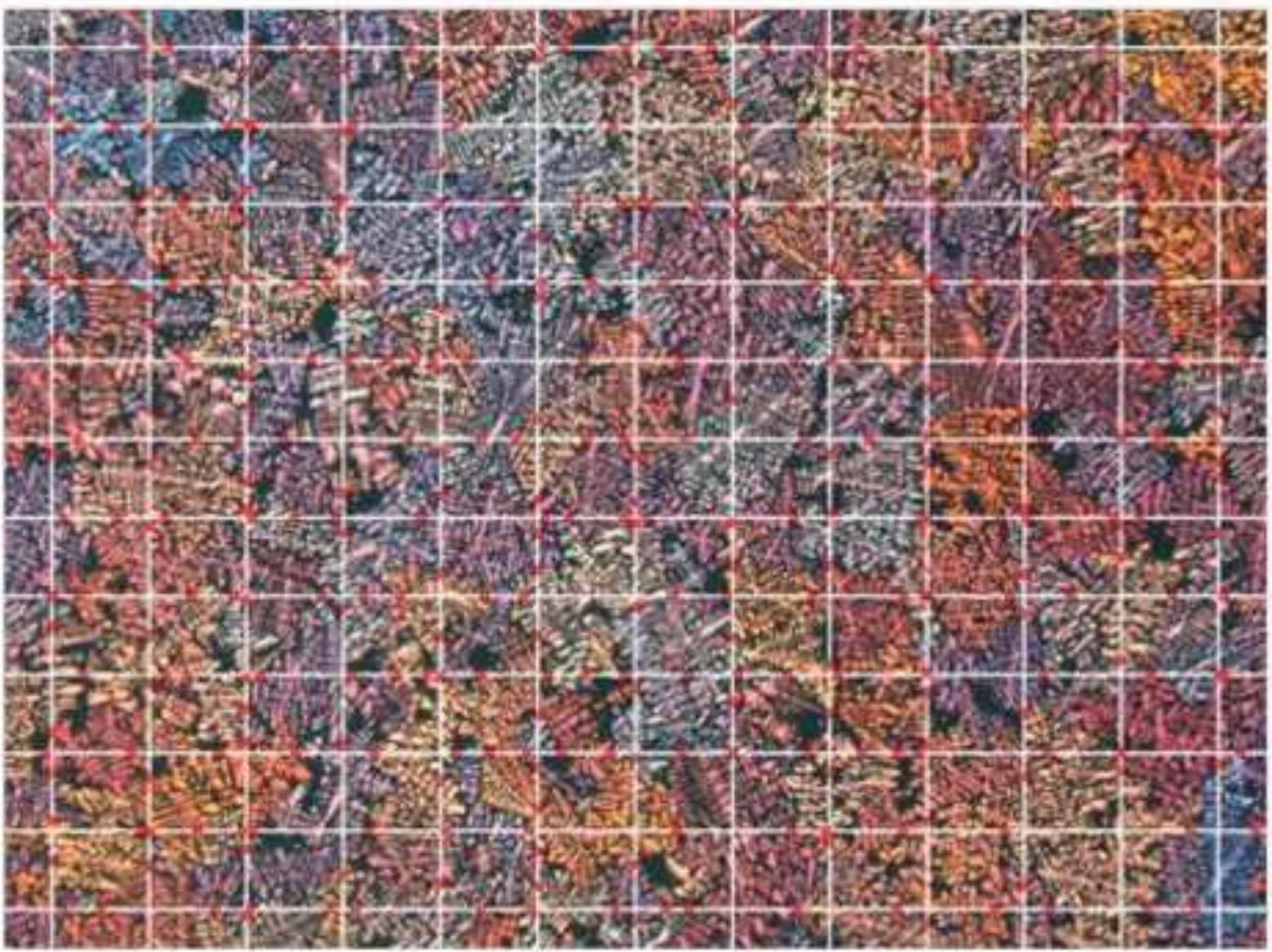



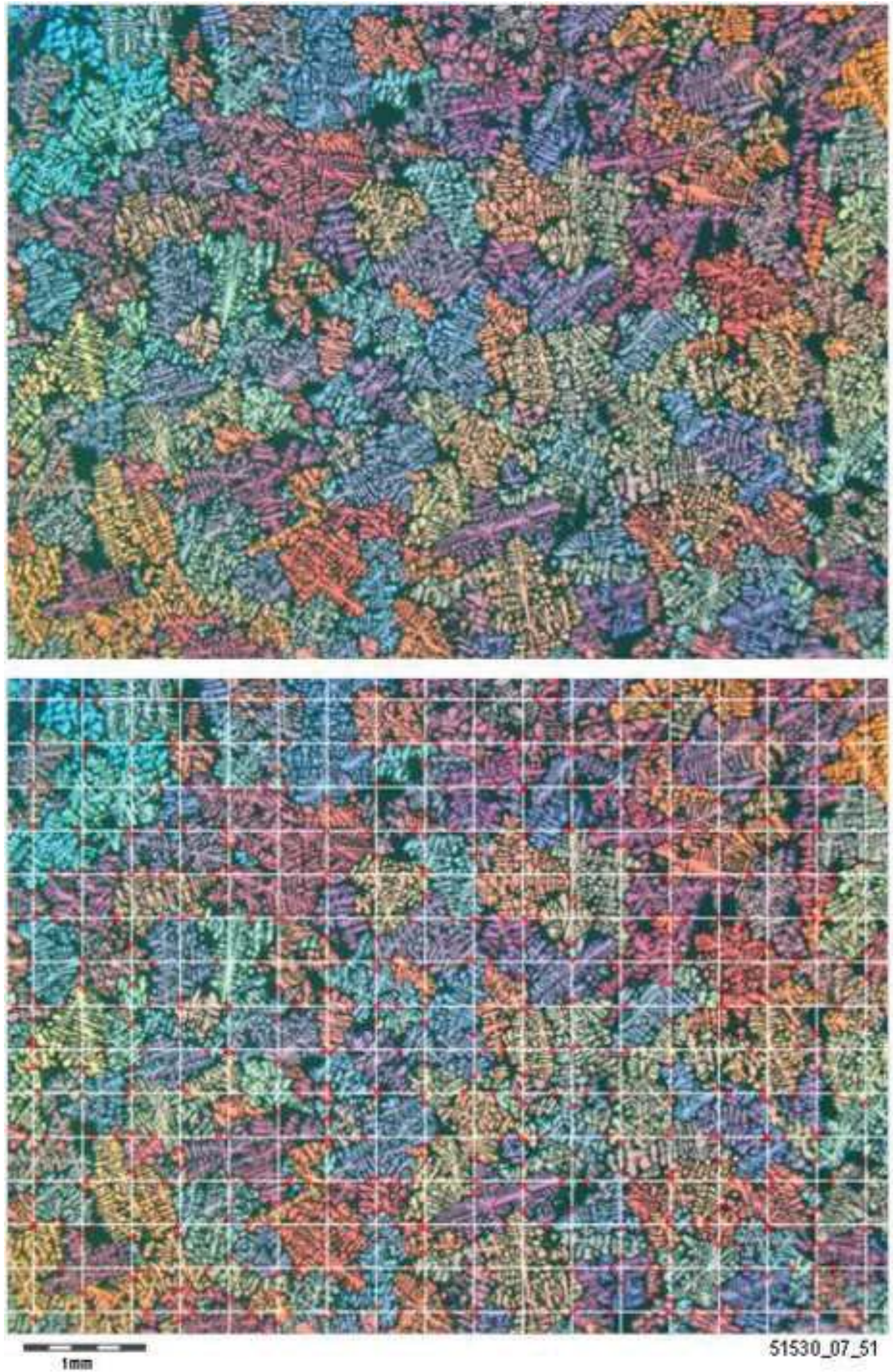